УДК 37.02

\title{
СИСТЕМА ДИСТАНЦИОННОГО ОБУЧЕНИЯ СВЯЗНОЙ РЕЧИ МЛАДШИХ ШКОЛЬНИКОВ (В КОНТЕКСТЕ ТЕХНОЛОГИИ УКРУПНЕНИЯ ДИДАКТИЧЕСКИХ ЕДИНИЦ)
}

\author{
Алферьева-Термсикос Валерия Борисовна \\ магистрант \\ ФГБОУ ВО «УлГПУим. И.Н. Ульянова»
}

\begin{abstract}
Аннотация: В статье представлена педагогическая модель дистанционного обучения связной речи младших школьников (в контексте технологии укрупнения дидактических единиц). Автором охарактеризованы эффективные информационные средства обучения; оптимальные для онлайнформата педагогические методы, способствующие развитию культуры речи; методологические принципы и организационные формы проведения занятий; а также необходимые для педагога soft-компетенции.
\end{abstract}

Ключевые слова: развитие связной речи младших школьников, технология укрупнения дидактических единиц (УДЕ), дистанционное обучение, метод укрупнения учебных задач, метод противопоставления, инсайт-метод, интеллект-карта, интерактивное упражнение, «дерево решений», кластер, «soft skills» учителя начальных классов

\section{DISTANCE LEARNING SYSTEM OF CONNECTED SPEECH OF PRIMARY SCHOOLCHILDREN (IN THE CONTEXT OF THE TECHNOLOGY OF INCREASING DIDACTIC UNITS)}

\section{Alfer'yeva-Termsikos Valeriya Borisovna}

\begin{abstract}
The article presents a pedagogical model of distance learning of coherent speech of primary schoolchildren (in the context of the technology of enlarging didactic units). The author has characterized effective information learning tools; pedagogical methods that are optimal for the online format, contributing to the development of a culture of speech; methodological principles and organizational forms of conducting classes; as well as soft-compensation necessary for a teacher.
\end{abstract}

Key words: development of coherent speech of primary schoolchildren, technology of integrated didactic units (IDU), distance learning, method of enlarging 
educational tasks, method of opposition, insight method, mind map, interactive exercise, «decision tree», cluster, «soft skills» primary school teachers.

Важным критерием в оценке культуры и образованности личности является «связная речь». Применительно к выпускнику начальной общеобразовательной школы данным термином характеризуется высокий уровень владения устной и письменной речью: умение свободно и связно выражать собственные мысли в форме монолога / диалога в соответствии с ситуацией общения; умение аргументировать собственное отношение к описываемому в высказывании объекту / явлению; умение строить высказывание в соответствии с законами логики; владение средствами художественно-языковой выразительности. В Федеральном государственном образовательном стандарте (ФГОС НОО) [10] среди предметных результатов овладения основной образовательной программы начального общего образования (ООП НОО) области «Филология» (курсы «Русский язык», «Литературное чтение», «Родной язык и литературное чтение на родном языке») можно выделить составляющие категории «связная речь»:

- позитивное отношение к правильной устной и письменной речи;

- владение нормами русского и родного литературного языка (орфоэпическими, лексическими, грамматическими) и правилами речевого этикета;

- осознанное восприятие художественной литературы, т.е. способность продуцировать текст, содержащий аргументированную оценку поступков литературных персонажей;

- владение приёмами интерпретации и преобразования текстов;

- владение коммуникативно-эстетическими возможностями родного языка.

Таким образом, педагогическая система работы по формированию речевых умений учащихся начальной школы состоит из задач, содержание которых соответствует вышеперечисленным умениям.

Среди метапредметных результатов освоения $\mathrm{OOH} \mathrm{HOO}$ в образовательном стандарте указано «активное использование речевых средств и средств информационных технологий (ИТ) для решения коммуникативных и познавательных задач», что полностью соответствует формату дистанционного обучения, актуальному в современных реалиях. Исследователями отмечено, что применение компьютерных образовательных технологий позволяет сочетать 
наглядность с вербальными методами обучения, что способствует осознанному оперированию понятиями и закреплению их в памяти, т.е. обучение в дистанционном режиме способствует развитию визуального мышления младшего школьника для получения продуктивных результатов [12, с. 372].

Моделирование занятий в дистанционном формате предполагает применение современных образовательных технологий, позволяющих младшим школьникам самостоятельно выстраивать собственную систему знаний. Для решения данной задачи наиболее эффективно применение перспективного направления современной педагогики - технологии укрупнения дидактических единиц (УДЕ), которая позволяет оптимизировать учебный процесс, в результате которого младший школьник может избежать информационной перегрузки, поскольку материал усваивается учеником структурированно, крупными блоками [3, с. 19].

В 1-4 классах процесс формирования связной речи базируется на усвоении комплекса лингвистических понятий: морфологических («имя существительное», «имя прилагательное», «глагол», «местоимение», «предлог»); синтаксических («предложение», «подлежащее», «сказуемое», «словосочетание»); словообразовательных («корень», «приставка», «суффикс», «окончание», «однокоренные слова») и др. [9, с. 238]. Поэтому организация дистанционного процесса усвоения лингвистического понятия, сложной гносеологической категории, основывается на применении информационных средств, способствующих овладению учащимися совокупности знаний о существенных свойствах предметов и явлений окружающей действительности, связей и отношений между ними. На этапе теоретического объяснения нового материала в соответствии с концепцией технологи УДЕ необходимо объединить знания о понятиях, размещённых в разных разделах русского языка или литературного чтения. Реализовать данную задачу можно с помощью интеллектуальных (ментальных) карт, спроектированных на платформе Lucidchart, MindMeister, Canva (рис. 1). 


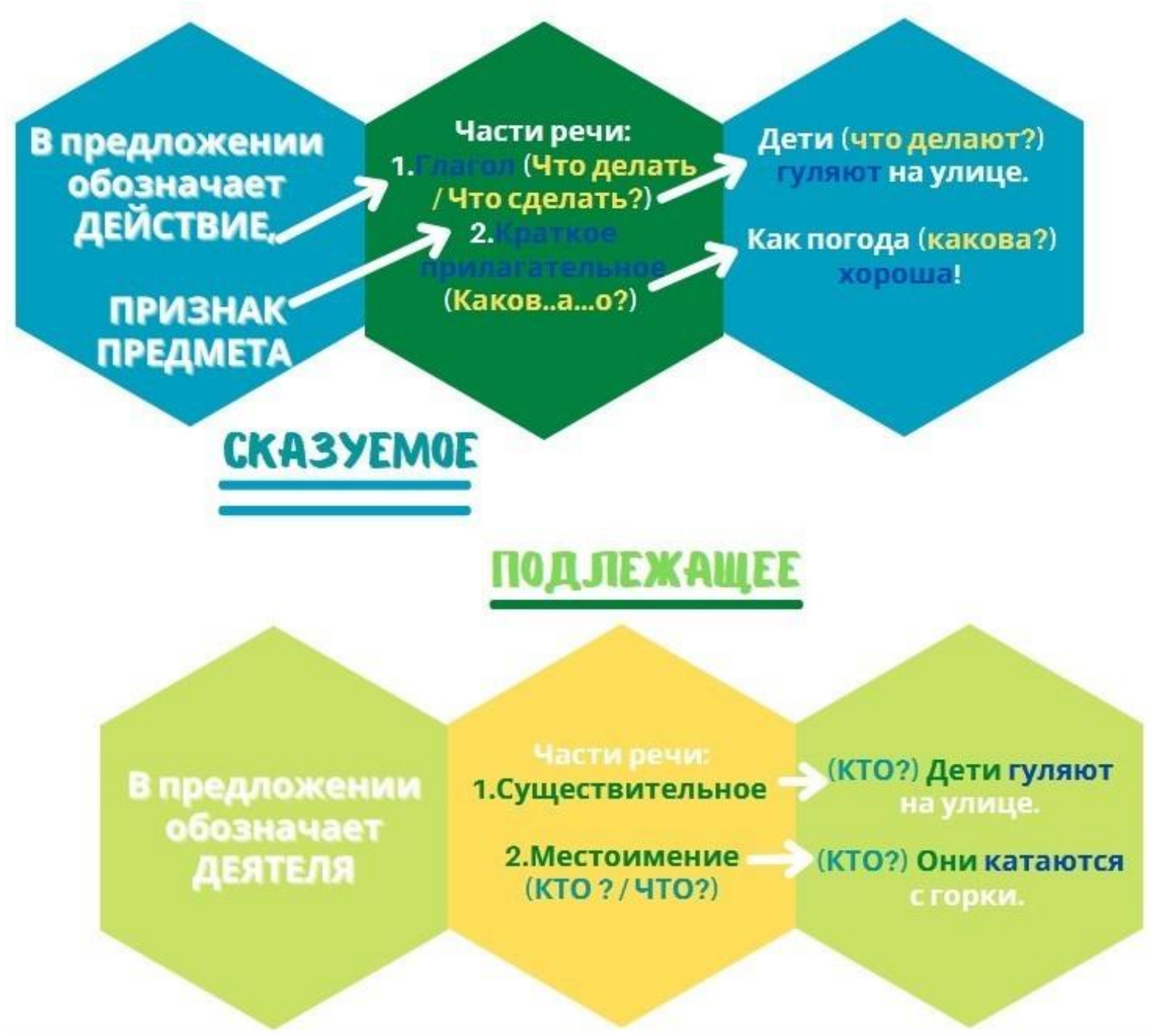

\section{Рис. 1. Интеллект-карта «Грамматическая основа предложения», разработанная с помощью сервиса Canva.com}

Крупноблочное построение программного материала в соответствии с методом укрупнения учебных задач по технологии УДЕ позволяет рассмотреть новую информацию целостными группами родственных единиц. Предметная задача - упражнение, в котором переход от одного действия к другому и есть укрупнение [1, с. 225]. Согласно методу укрупнения учебных задач, упражнение обеспечивает следующие этапы обучения - «завершение уяснения» и «закрепление», а также «обобщение» и «автоматизацию», что, в итоге, приводит к полному овладению действием и преобразование в умение и навык. Подбирая и разрабатывая задания, учитель выбирает родственные понятия из учебной темы, объединяет их в пары и выстраивает учебный процесс на одновременном и совместном их изучении. Подобное пространственное и временное сближение позволяет преобразовывать 
разрозненные знания младших школьников в целостную систему. В рамках дистанционного режима обучения на этапе выполнения практических заданий для закрепления изученных знаний о лингвистических понятиях учитель начальных классов с помощью сервиса LearningApps.org сможет создать мультимедийные интерактивные упражнения (рис. 2).

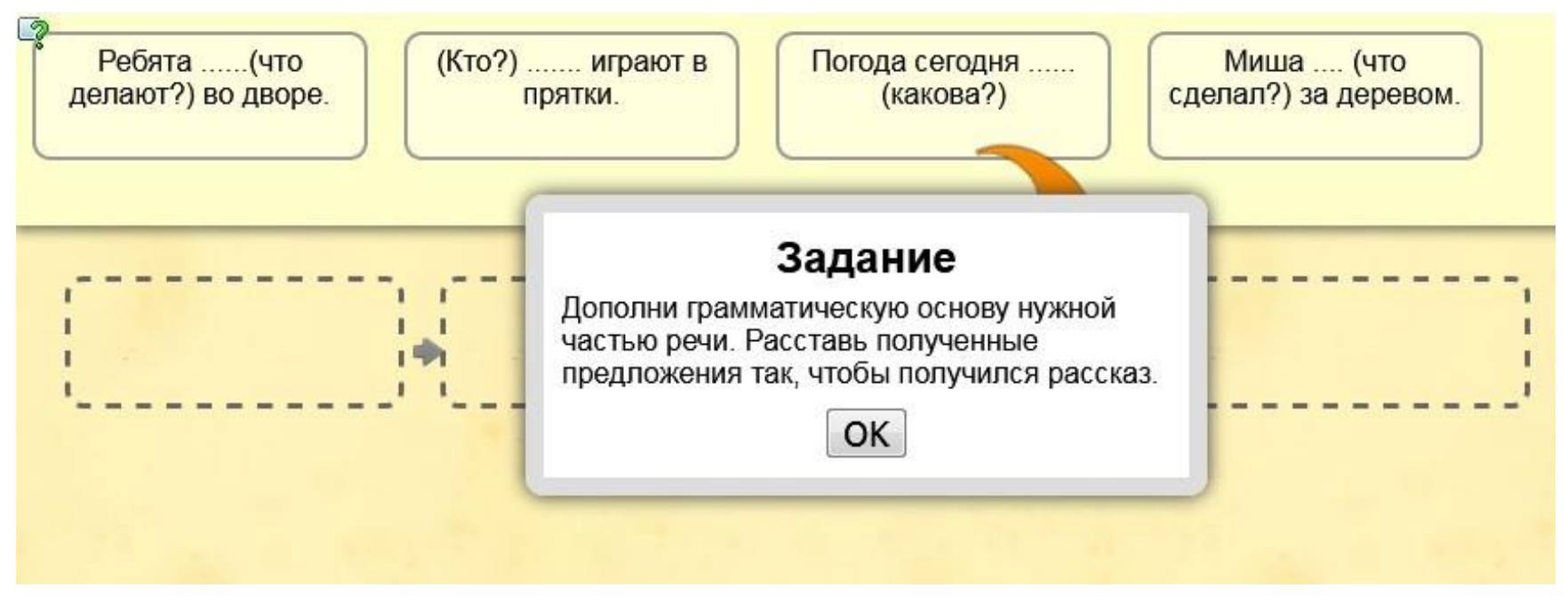

\section{Рис. 2. Интерактивное упражнение, созданное на платформе LearningApps.org}

Стратегия организации языкового пространства при дистанционном обучении также включает реализацию эффективного метода технологии УДЕ противопоставления, которое может быть при соотношении учебных текстов, лексических единиц (синонимов и антонимов, в том числе начальных понятий контекстных синонимов и антонимов), синтаксических единиц (главных и второстепенных членов предложения) и проч. Виртуальным информационным средством, с помощью которого учащиеся смогу противопоставить исследуемые языковые объекты, является «Дерево решений» [5, с. 195]. Данный способ представления информации с вопросами к ней в иерархической структуре в контексте УДЕ позволяет учащемуся выполнить последовательный анализ информации, сделать вывод на основе противопоставления языковых объектов. Эффективными онлайн платформами для составления «дерева решений» являются Lucidchart, Planetcalc, Knowflow, а также программное обеспечение Edraw Max (рис. 3). 


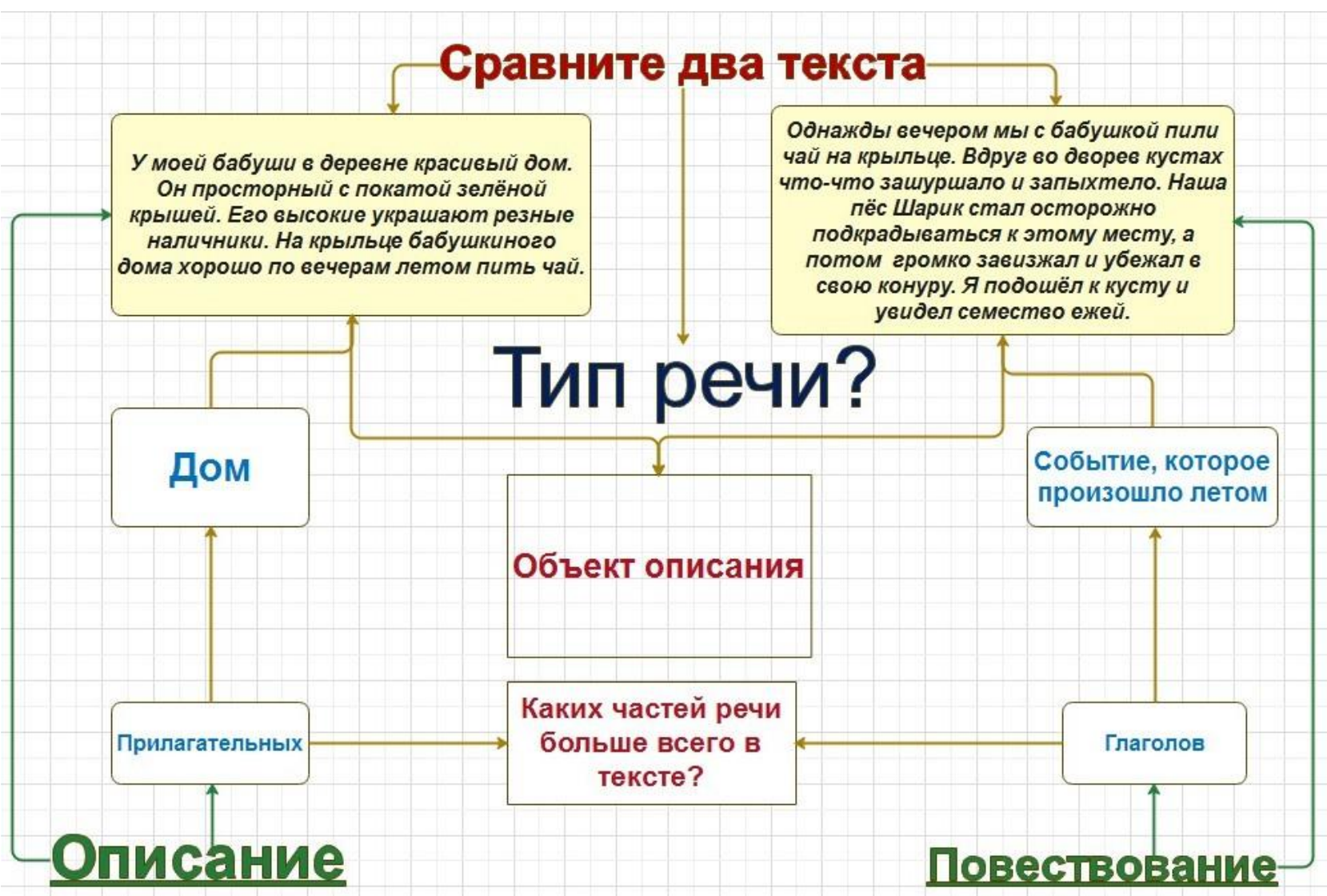

\section{Рис. 3. «Дерево решений», составленное с помощью программного обеспечения Edraw Max}

Поскольку технология укрупнения дидактических единиц представляет собой систему обучения, которая построена на содержательном обобщении учебного материала посредством блоков-единиц усвоения [6], то в дистанционном режиме наиболее оптимальным для объяснения нового материала является инсайт-метод, механизм применения которого заключается в переструктурировании педагогом условий учебного задания таким образом, чтобы младший школьник на основе собственного витагенного опыта нашёл его решение [3, с. 257]. В качестве информационного средства обучения в данном случае может быть задействован кластер, способ графической организации материала в виде древовидной схемы. Моделировать кластеры, в том числе интерактивные, возможно на платформах Creately.com, Venngage.com (рис. 4). 


\section{Приводим аргументы в сочинении}

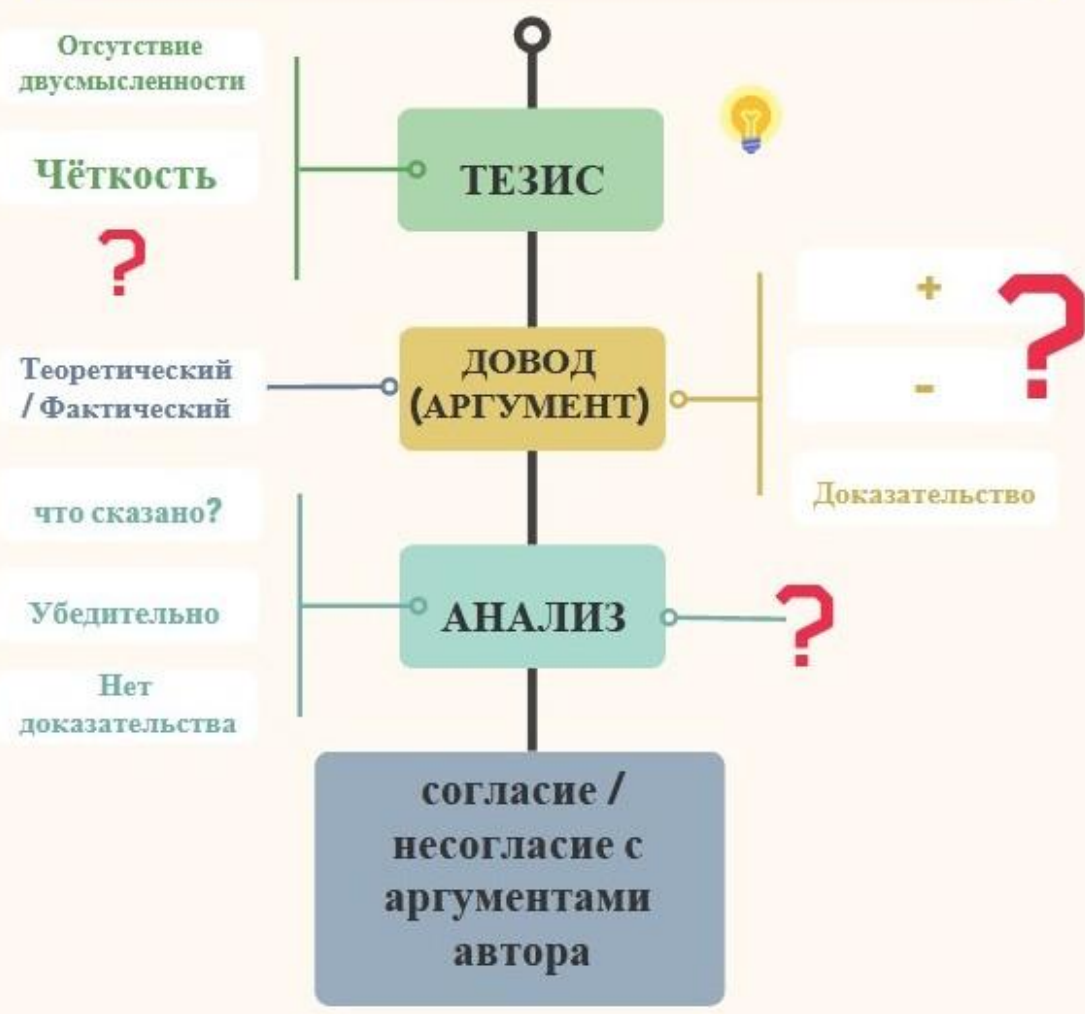

\section{Рис. 4. Кластер «Приводим аргументы в сочинении», составленный на платформе Venngage.com}

Необходимо отметить, что в контексте применения технологии УДЕ учащимся представляется видоизменённый кластер с иерархичной структурой, где часть элементов учащимся необходимо заполнить самостоятельно. Поскольку дети в младшем школьном возрасте мыслят «формами» (конкретными образами), то данное информационное средство визуальной наглядности способствует развитию мышления учащихся.

Организация педагогического процесса по формированию связной речи в дистанционном режиме предполагает разработку заданий деформированного типа, позволяющих реализовать следующие методологические принципы технологии УДЕ: принцип связи теории и практики, принцип обратных связей, принцип подчинённости языковых знаний и речевых навыков коммуникативным умениям.

Упражнения должны содержать интерактивные элементы и анимационные эффекты для того, чтобы за счёт сочетания текстовой, 
графической и аудио составляющей у младших школьников было задействовано полисенсорное восприятие информации, активизация которого способствует бессознательному запоминанию.

Интерактивные задания по развитию речи для практической отработки употребления средств языковой выразительности, орфоэпических, фонетических, лексических норм могут включать:

- редактирование текста;

- выбор слов в соответствии с контекстом;

- постановка ударения;

- определение правильной формы слова и тд.

Удобный инструментарий онлайн-сервисов Nitforyou.com, ThingLink, Simpleshow, Wordwall (рис. 5) позволяет учителю за небольшой отрезок времени спроектировать интерактивные задания, которые можно представить учащимся в режиме «демонстрация экрана» во время видеоконференций Zoom, Google Meet.

\section{невежда скрытный эффектный эффективный невежа скрытый}

\section{Обладать ... характером; Кто мало читает, тот....... Принять ... меры против нарушителей дисциплины}

$\equiv$ Отправить Ответы

\section{Рис. 5. Интерактивная карточка «Лексическое значение слов», составленная с помощью сервиса Wordwall}

Система дистанционного обучения связной речи младших школьников в контексте технологии укрупнения дидактических единиц основывается на грамотном включении охарактеризованных выше информационных средств и 
педагогических методов. Для чего учителю необходимо обладать соответствующим soft-компетенциями:

1. Владение современными цифровыми технологиями:

- информационная грамотность: поиск и фильтрация данных, управление данными, информацией и цифровым содержанием [11, с. 33];

- умение подобрать к содержанию разработанного дидактического материала программные продукты для создания качественного интерактивного обучающего ресурса;

- творческое использование цифровых ресурсов (умение создавать новое интерактивное средство обучения);

- способность интерпретировать и воспроизводить данные с помощью мультимедиа, а также оценивать и применять новые знания, полученные из цифровой среды [7, с. 344];

- умение использовать цифровые технологии в комплексе (несколько сервисов одновременно).

2. Ориентация в современных образовательных тенденциях, информационной среде, т.е. система «soft skills» («гибких навыков»):

- способность к самопрезентации, непрерывному профессиональному образованию (повышению квалификации);

- быстрая адаптация педагога к проблемной, кризисной ситуации, которая позволяет ему ослабить или смягчить её требования, нейтрализовать эмоциональное напряжение («копинг-поведение) [8, с. 10];

- социализация в сети Интернет: умение создать группу класса в социальных сетях; разработать сайт на платформе Google для размещения обучающих авторских материалов; участие в профессиональных конференциях в дистанционном формате для обмена опытом с другими педагогами;

- способность к анализу информационных ресурсов (соответствия их инструментария интеллектуальным особенностям детей младшего школьного возраста в том числе из категории VII вида с OB3 и ЗПР);

- умение продуцировать эффективные и креативные способы передачи информации в онлайн-режиме;

В отличие от «hard skills» (умений, составляющий профессиональную квалификацию, владение предметной областью) «soft skills» (метапредметные компетенции) являются той группой личностных характеристик, благодаря которой учителю возможно смоделировать процесс дистанционного обучения в соответствии с определёнными педагогическими целями и задачами. 
Целью дистанционного обучения связной речи младших школьников является моделирование педагогического процесса в онлайн-режиме, способствующего овладению младшими школьниками коммуникативнонормативным компонентом речи.

В соответствии с данной целью необходимо выделить следующие задачи:

- Формирование лингвистических понятий;

- Развитие навыков соблюдения и практического применения языковых норм (орфоэпических, грамматических, лексических, стилистических, орфографических, пунктуационных);

- Развитие культуры речи, т.е. формирование таких её коммуникативнонормативных компонентов как логичность, точность, выразительность, уместность, содержательность (богатство), чистота.

Организация дистанционного обучения связной речи младших школьников в контексте технологии УДЕ должна соответствовать специальным методологическим принципам:

1. Принцип когнитивной визуализации предполагает обеспечение учителем познавательной функции наглядных обучающих средств (интеллекткарт, кластеров, интерактивных заданий/ карточек, презентаций, видеороликов, интерактивных инструкций).

2. Принцип интерактивности - организация «обратной связи» в учебном процессе. Данный принцип обозначает не только консультацию (устную / визуальную) со стороны учителя, но и содержание разрабатываемого информационного материала (наличие гиперссылок на правильный вариант ответа, «всплывающие окна» с подсказками, наличие комментария с указанием на ошибку и проч.).

3. Лингвометодический принцип связи теории и практики - на одновременное выполнение противоположных операций, из которых состоит курс русского языка.

3. Принцип обратных связей реализуется через выполнение учащимися «деформированных» упражнений и текстов. Данные задания содержат недостающие данные, а также операции, предполагающие нахождение и продолжение закономерности, что придаёт ходу мыслительных операций новое качество.

4. Принцип достижения системности через одновременное изучение противоположных лингвистических понятий. 
5. Принцип подчинённости языковых знаний и речевых навыков коммуникативным умениям основывается на осознании учащимся коммуникативно-смысловой значимости языка.

Исходя из специфики процесса дистанционного обучения связной речи, наиболее оптимальными организационными формами являются:

- Видеолекции с включением презентационного материала для знакомства учащихся с новой информацией.

- Видеоконференции для проведения фронтальных опросов, организации «круглых столов» с обсуждением проблемных задач.

- «Чат-дискуссии» - обмен мнениями учащихся при подготовке к выполнению проектов (распределение обязанностей), конкурсным работам и викторинам.

- Индивидуальный интерактив для проведения проверочных работ.

- Индивидуальная / групповая работа на специально созданном учителем сайте класса (презентация и размещение учащимися своих творческих работ).

Необходимо отметить, что главной особенностью фактологической стороны содержания дистанционного образования является наличие компьютерной информационной среды, включающей базы информации (гипертекст и мультимедиа), имитационный обучающий программный материал, электронные коммуникации [4, с. 58]. Таким образом, учитель отвечает не только за техническую составляющую, но и за содержательную и методологическую, т.е. разработку информационных средств и реализацию специально подобранных методов.

Педагогическая модель дистанционного обучения связной речи младших школьников в контексте технологии укрупнения дидактических единиц, включающая все описанные выше элементы, представлена на рис. 6. 
Цель - организачия педагогического прочесса в онлайн-режиме, способствующего овтадению младиими икольниками комминикативно-нормативным компонентом речи.

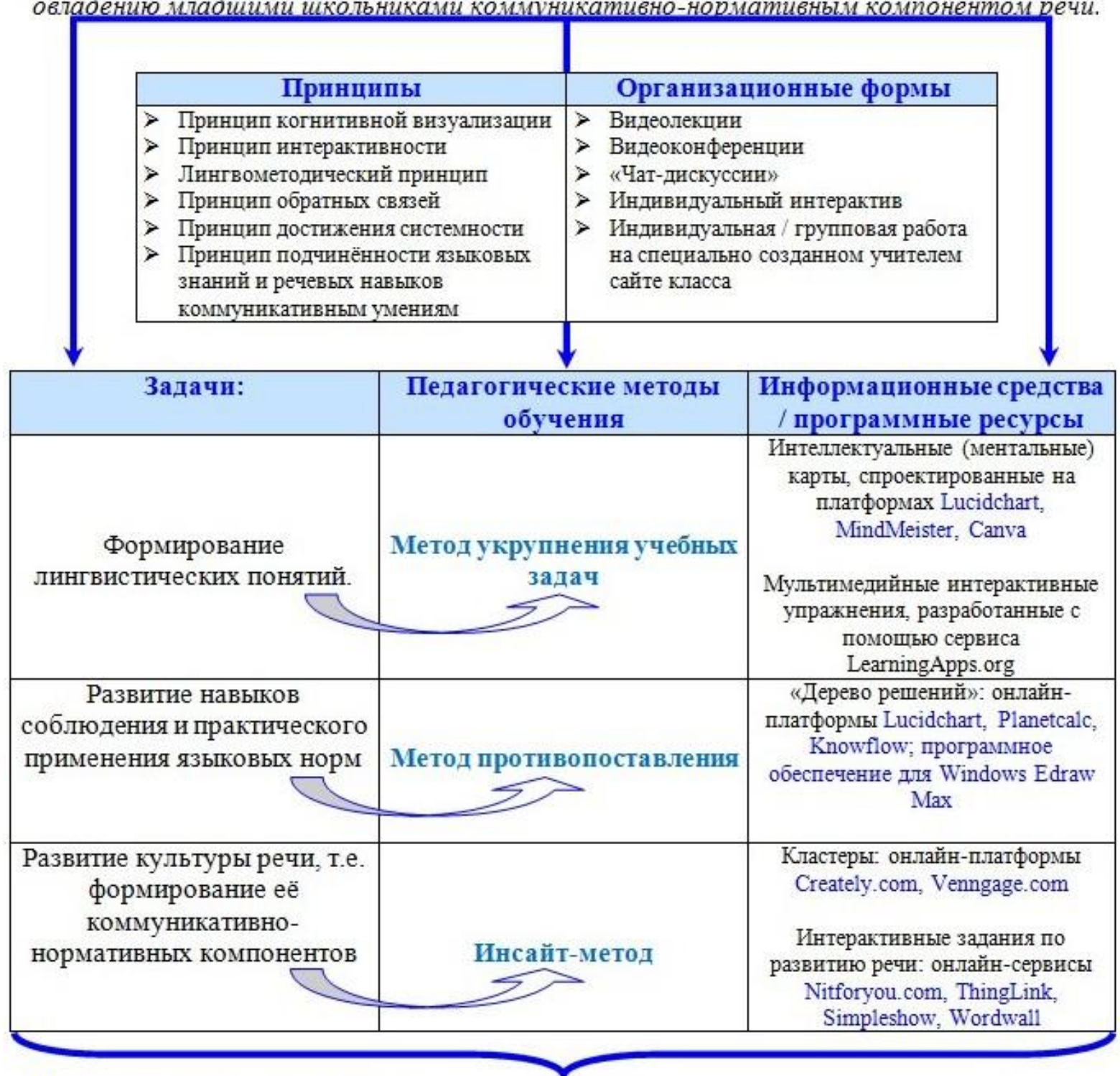

Педагогические условия, обеспечиваюшие эффективность дистанционного обучения связной речи младших школьников

$\checkmark$

Soft- skills педагога начального образования:

- владение современными цифровыми технологиями,

- ориентация в современньг образовательньх тенденциях, информационной среде.

Организация компьютерной информационной среды, включающей базы информации

(гипертекст и мультимедиа), имитационный обучающий программный материал.

Для развития речевой деятельности посредством дидактического укрупнения необходимо использование комплекса интерактивных упражнений, включающих необычную

компоновку языкового материала

\section{Рис. 6. Педагогическая модель дистанционного обучения связной речи} младших школьников в контексте технологии УДЕ 


\section{Список литературы}

1. Алферьева-Термсикос В.Б. Методический аспект применения технологии укрупнения дидактических единиц на уроках русского языка в начальной школе // Инновационные воспитательные практики: детский сад, школа, ВУЗ: материалы Всероссийской научно-практической конференции с международным участием, апреля 2021 г. / Отв. ред. М.Г. Заббарова. Ульяновск: ФГБОУ ВО «УлГПУ им.И.Н. Ульянова», 2021. - С. 223-229.

2. Алферьева-Термсикос В.Б. Механизм применения инсайт-метода на уроках русского языка в начальной школе по технологии укрупнения дидактических единиц (УДЕ) // Инновационные образовательные практики: Детский сад, Школа, ВУЗ. Материалы Всероссийской научно-практической конференции с международным участием. Под ред. М.Г. Заббаровой. Ульяновск: ФГБОУ ВО «УлГПУ им И.Н. Ульянова», 2020. - С. 256-259.

3. Алферьева-Термсикос В.Б. Применение метода укрупнения учебных задач как средство развития обучаемости в начальной школе // Теория и практика приоритетных научных исследований. Сборник научных трудов по материалам $\mathrm{X}$ Международной научно-практической конференции (г. Смоленск, 16 декабря 2019 года). - Смоленск: МНИЦ «Наукосфера», 2019. C.19-21.

4. Заббарова М.Г., Дормидонтова Л.П., Березова Н.А. Педагогические технологии начального образования: теория и практика реализации в образовательных организациях: учебное пособие. - Ульяновск: ФГБОУ ВО «УлГПУ им. И.Н. Ульянова», 2021. - 203 с.

5. Кондакова Л.В. Использование интерактивных методов обучения на уроках литературного чтения // Филологические аспекты начального образования: истории, современность и перспективы развития: материалы Всероссийской научно-практической конференции молодых ученых. - М.: МПГУ. 2019. - С. 194-197.

6. Микерова Г.Г. Система обучения русскому языку по технологии укрупненных дидактических единиц в начальной школе // Современные технологии в образовании. - 2019. - № 19. - С. 149-154.

7. Петрякова С.В., Фатеева Н.Б., Петрова Л.Н., Алимарданова Н.А., Симачкова Н.Н. Цифровые компетенции преподавателей учебных заведений // Образование и право. - 2021. - №3. - С. 343-346. 
8. Поникарова В.Н., Педагогическая система формирования софт скиллз: монография. - Курск: изд-во ЗАО «Университетская книга», 2020. - 153 с.

9. Рамзаева Т.Г., Львов М.Р. Методика обучения русскому языку в начальных классах: Учеб. пособие для студентов пед. ин-тов по спец. № 2121 «Педагогика и методика нач. обучения» [Электронный ресурс]. - Режим доступа: http://pedlib.ru/Books/4/0033/4_0033-238.shtml (17.08.2021)

10. Федеральный государственный образовательный стандарт начального общего образования [Электронный ресурс]. - Режим доступа: http://www.consultant.ru/document/cons_doc_LAW_96801/ea5d7777caea0f829ef08 8881c72c46bf592482c/. (20.08.2021)

11. Чавдарова-Костова С.Г. Цифровые компетентности учителей и преподавателей в системе высшего образования в мире неопределенности и непоследовательности // Новая психология профессионального труда педагога: от нестабильной реальности к устойчивому развитию. - 2021. - №1 . - С. 32-35.

12. Чибухашвили В.А. Возможности и перспективы использования компьютерных технологий в преподавании русского языка и культуры речи // Современные технологии в преподавании русского языка. Сборник материалов международной научно-практической конференции, к 60-летию кафедры методики преподавания русского языка Московского педагогического государственного университета. - М.: МПГУ, 2020. - С. 371-375.

(C) В.Б. Алферьева-Темсикос, 2021 